\title{
Towards a sustainable and fit-for-purpose health workforce - lessons from New Zealand
}

\author{
Reforms underway in New Zealand are \\ designed to significantly increase \\ workforce productivity
}

$\mathrm{t}$ is true that most ill and injured New Zealanders currently receive appropriate and timely health care, but viewed as a whole, and considering health outcomes in Maori and poorer urban and rural communities, ${ }^{1,2}$ the New Zealand health system is something of a "curate's egg". I suggest that the New Zealand health workforce is neither sustainable nor fit-for-purpose. This situation is largely a result of systemic issues, which are being addressed. Any perception of system inadequacy is exaggerated by New Zealanders' high expectations for health care relative to the country's small population and modest wealth (by OECD [Organisation for Economic Co-operation and Development] standards).

As is true for all OECD member nations, New Zealand is affected by a global mismatch of health service demand, supply and affordability. ${ }^{3}$ The World Health Organization estimates a worldwide health worker shortage greater than New Zealand's total population. ${ }^{4}$ Another OECD report in this context argued that New Zealand's reliance on immigrant health workers is unsustainable. ${ }^{5}$

Consequently, new national health agencies have adopted "responsive" health workforce planning principles.

\section{Citizenship and living forever well}

New Zealand is a social democracy. Generally shared values of citizenship arise from a common history of immigration, in response to fundamental legislation, such as the 1938 Social Security Act, and from a treaty between indigenous Maori and the colonising British. ${ }^{6}$ These values include an inherent contract to work, and hence to contribute directly and indirectly to society, and to support those who cannot. There are also expectations of social mobility, largely by way of state-funded education, and a similar assumed birthright of unlimited access to necessary, excellent and unconstrained health care. The latter establishes the milieu of health service and related workforce planning.

Health Workforce New Zealand Wellington, New Zealand.

d.gorman@ auckland.ac.nz

MJA Open 2012; 1 Suppl 3: 32-36 doi: 10.5694/mjaoll.11583

\section{Health demand in New Zealand in ten years' time}

On the basis of the ageing of the New Zealand community alone, the New Zealand Institute of Economic Research (NZIER) predicted in 2005 that between $40 \%$ and $70 \%$ more health workers would be needed by 2021 to maintain the then current health service levels. ${ }^{7}$ This prediction was based on an incorrect assumption of stable worker productivity, $^{8}$ and the $40 \%$ to $70 \%$ range was contingent on various scenarios of disease compression, and so on. The NZIER predictions are demonstrably very optimistic if the following factors are included in any demand forecast: ongoing workforce feminisation; ${ }^{9}$ the shifts towards parttime work and retirement, and in migration trends; 5,10 the increase in high-technology and often low-utility but expensive end-of-life care measures; and increasing health service consumption by an increasingly affluent and "health-anxious" worried-well middle class. ${ }^{11}$ Finally, and somewhat perversely, medicine's success in managing "acute" disease is manifest to some degree as an increased prevalence of complicated and costly chronic diseases in older people.

The sobering observation here for health workforce planning, however, is that on the basis of the number of health-service providers and trainees in New Zealand in 2010, and modelling for effects of feminisation, part-time work, recruitment and career choice, migration and retirement, none of the medical disciplines will have enough practitioners in 2021 to meet even the best-case NZIER scenario (ie, $140 \%$ of the 2005 base)..$^{7}$ The status quo is not an acceptable option to meet the demand challenge, and many, if not most, health services will need to be changed; this will necessarily require a reform of service configurations and models of care. This recognition also leads to the need to adopt the core design processes of development of an inclusive health system intelligence ${ }^{12}$ and clinician-led disruptive innovations of business-asusual. ${ }^{6,13,14}$

\section{Clinician-led disruptive innovations of health care}

Many argue that the solution to any health service demand-supply mismatch lies in management of waste, better integration of primary and secondary care and in a sequential shift of care setting from the hospital to the community clinic and into the home. ${ }^{15}$ However, such a distributed model of care is only affordable if it results in fewer new hospital beds and hospital-based specialists. Some enabling technologies and a revision of funding and reward systems are also essential. ${ }^{16}$

Consider this scenario:

Mary is an elderly widow who lives in a remote area of Northland and has insulin-dependent diabetes mellitus. She is unwell and has frequent falls. Her daughter consequently takes a day off work and drives her to see her family doctor. The family doctor is worried and orders some blood tests. Two days later, the results are available and the nurse from the clinic rings and asks Mary to come back. Mary's daughter takes another day off and returns with her to see the 
family doctor, and a decision is made there to refer Mary to a physician who has an interest in diabetes and who visits a local regional hospital. The next appointment is in 3 months. Mary goes home, continues to have falls and two of these result in shortterm hospitalisations at the local community hospital. Three months elapse and Mary's daughter takes a third day off work to drive her to see the specialist. A complete change in insulin regimen is decided. Mary and her daughter go home via the hospital pharmacist, and Mary will be visited by a district health nurse.

This vignette is an exposition of slow, low-quality, "transactional", and consequently expensive, care. Thankfully, it also involves a compliant patient and attentive family member.

Compare it with the following:

Because of a request from Mary's daughter, a district nurse visits and pricks Mary's finger to measure blood glucose and glycated haemoglobin levels with a small test unit she has in her car. The results are uploaded onto Mary's "Facebook-type" health record through the nurse's phone. The nurse texts the family doctor who goes online, uses the password Mary has provided, and looks at the values. The family doctor then texts the diabetes specialist, who looks at Mary's record on his phone. A complete change in insulin regimen is decided and an e-prescription is sent to the local pharmacist.

In this scenario, Mary does not leave home and her daughter does not have any time off work. The entire process takes a few hours. Mary does not fall and the local hospital does not admit her. Two enabling technologies are needed here - the testing unit, which already exists and is cheap to operate, and an accessible shared health care record. A single patient identifier is needed and each provider similarly needs coding, both of which exist in New Zealand. Another essential enabler here is a reward system, which is not rigidly transactional and is based on, but is not limited to, remuneration. The track record of paying health care providers for performance is not good. ${ }^{16}$ Simple fee-for-service systems often result in relative overservicing, are counter-innovative, as the model of care is defined by the fee schedule, and are transactional, and hence encourage competition as compared with collaboration. An actuarial approach is needed for chronic disease, along with a "tight (quality outcome determinations)-loose (service delivery models)-tight (measurement of outcomes against the agreed quality criteria)" approach by core funding agencies to capitation. Providers should be predominantly incentivised for quality outcomes, as compared with outputs, and this outcome performance should be measured, as much as possible, at the organisational as compared to the individual provider level. The ambition is that provider "groups" own both the quality health outcome risk and the financial risk.

As an illustration, the capitation rate for a cohort of patients with diabetes could be determined by two related outcome measures: the hospital admission and attendance rate for those people registered with the providers and who are admitted for a problem related to diabetes; and the incidence of people registered with the providers who have diabetes and who go into renal failure. ${ }^{17}$

Achievement of contracted outcomes within a 5- or 10year financial capitation period will by necessity require innovative, collegial and interprofessional practice, and a shift to patient-centred and patient-directed care. The latter warrants another essay.

\section{The affordability of health care in New Zealand}

The discussion above is based on a "simple" supply-anddemand consideration. The other element here is that of affordability. New Zealand's per capita spending on health is lower than the OECD average, but the trends have been parallel since 1980. Treasury data for 2012 show that health spending was almost $10 \%$ of gross domestic product (GDP); it was about $20 \%$ of total government expenditure; and almost $50 \%$ of all the new money in the 2009, 2010, 2011 and 2012 budgets was allocated to funding for "public" health services, marking the "tipping point" of affordability. From 1950 to 2011, the wealth of New Zealand, as measured by GDP, grew by $144 \%$, whereas spending on health over the same period increased by $412 \%$. There are only two fundamental responses available to the government in this context, and these are to reduce the demand for health services and/or to reduce the cost of meeting that demand. A triad of strategies are consequently in place in New Zealand. In addition to attending to reform of governance and management systems, there is clinician-led reform of service configurations and models of care, and the related management of waste, and reform of service funding and provider reward systems. ${ }^{12,16}$

\section{Health workforce planning under conditions of uncertainty}

Evidence is the core of good health practice. The problem for health workforce planning is that scrutiny of relevant track records suggests that no one has ever got it right. Planning failures are made manifest by endemic cycles of feast and famine in regard to the number of workers and the job market. Feasts may coexist with famines, and the cycle is often rapid. Some aspects of the health workforce, such as the vacancy rates in public hospitals for nurses and midwives, are very sensitive to the overall economy and general labour market conditions. "Medical" discoveries, such as the infectious cause of peptic ulcers, are essentially unpredictable and can render large parts of the health workforce redundant, literally overnight. ${ }^{18}$ It is probable that the only truism about planning the health workforce is that any plan will inevitably be wrong.

This recognition can either be seen as an excuse to give up, resort to serendipity and rely on the vagaries of the marketplace, or as a stimulus to adopt principles that enable effective planning under conditions of uncertainty. Health Workforce New Zealand has adopted a clinical scenario-based planning approach. ${ }^{12}$ The logic is that health need drives planning and that subsequent service configurations and models of care determine the interactive solutions of information technology (IT) and 
Key recommendations of the Health Workforce New Zealand Service Forecast Teams that have been established to date*

\section{Service aggregate}

Common

recommendations

\section{Key service recommendations}

Employ funding models that support interdisciplinary care and innovative practice and where consumers and providers manage the outcome and financial risk.

Enhance communication between consumers and providers to enhance care coordination
Anaesthesia

Cancer

Diabetes

Eye health addictions

Establish regional oversight groups to recruit and deploy anaesthetists across health regions.

Establish a coordinated national population-based diabetes prevention program to reduce the burden of type-2 diabetes and screen for eye and renal complications.

Change the New Zealand Medicines Act 1981 to enable optometrists to prescribe glaucoma medications.

Rationalise and standardise child eye health screening services.

Ensure everyone with macular degeneration and low vision is assessed by an eye health professional with low vision expertise.

Provide teleconferencing to reduce health inequities in rural areas.

Use a mobile clinic in rural areas to address access issues.

Shift resources to enable earlier intervention for at-risk families, children and adolescents where there is evidence that such intervention reduces the burden and cost of disease.

Integrate primary and secondary services using stepped-care approaches to improve access and recovery in the community, and to reduce the burden and cost of concurrent mental and physical conditions.

Reduce system-wide costs by influencing pathways through high-risk mental health, care and protection, and justice services.

Proactively manage the impact of mental health problems on care for older people.

Develop the capacity and capability of the spectrum of selfcare support by enabling e-therapies, self-care or whanau (extended family) care and peer support.

\section{Mothers and babies}

Musculoskeletal health problems
Invest in and standardise telemedicine to enable the remote assessment of patients referred for tertiary-level services.

Begin postoperative adult orthopaedic trauma rehabilitation at admission

Invest in public health measures, including early interventions to improve fitness and diet in young adults and throughout adulthood.

Screen patients for potential osteoporosis and obesity.

\section{Key workforce recommendations}

Improve community health literacy and reward appropriate helpseeking and preventive health behaviour.

Employ doctors in roles that can only be undertaken effectively and safely by someone trained as a doctor.

Extend the roles of nurse practitioners and allied health professionals.

Upskill and support carers.

Extend the roles of anaesthesia technicians and medical officers to improve operating theatre productivity.

Expand the role of nurse specialists.

Diabetes nurse specialist prescribers to lead diabetes care using an integrated primary care model.

Develop an eye health community model that includes an increase in the role of optometrists.

Investigate the role and career pathway of ophthalmic nurse specialists within hospitals and other settings.

Develop a postgraduate diploma in ophthalmology for general practitioners and nurses.

Support an undergraduate degree in orthoptics.

Recruit gastroenterology nurse specialists for areas such as inflammatory bowel disease, hepatitis, colorectal cancer screening and surveillance, and colon polyp follow-up. Expand the gastroenterology workforce using nurses, allied health practitioners, dietitians and a range of assistants to provide assessment and management, including endoscopy.

Build capacity of specialist clinical workforces (psychiatry, psychology and mental health nursing) to support areas of future development and a significant change in roles.

Expand the role of e-health and related "virtual" mental health initiatives.

Implement a comprehensive midwifery internship.

Ensure that conservative management of musculoskeletal disorders, including pain, is a core competency for all general practitioners.

Increase emphasis on musculoskeletal teaching.

Develop a workforce of non-operative clinicians expert in conservative management of minor musculoskeletal disorders.

Increase the number of staff with expertise in geriatric management for postoperative medical care.

Increase the number of doctors trained in rehabilitation, including tertiary-level rehabilitation specialists and GPs with rehabilitation medicine as a special interest.

Develop and consolidate advanced scopes of practice for physiotherapists, especially in hospital outpatient roles. Extend musculoskeletal training of clinical nurse specialists.

* From www.healthworkforce.govt.nz 


\section{Key recommendations of the Health Workforce New Zealand Service Forecast Teams that have been established to date (continued)}

\section{Service aggregate}

Older people

Palliative care

Youth health

\section{Key service recommendations}

Increase the focus on home and community-based prevention and rehabilitative service options for older people, especially short-term interventions that maximise the potential for independence.

Use clinical specialists to increase the knowledge and skills of other health and support workers in the community and primary care (leveraging).

Gear up service and facility design within acute care to meet the needs of people over 65 years of age.

Develop managed clinical networks that are linked nationally.

Develop a funding model for primary care-based community palliative care.

Fund school-based health services, and youth health community services to meet specific communities' needs.

Do not focus health services for young people on a single issue (such as reducing violence, crime, alcohol and drugs, including tobacco use, and risky sexual behaviour); collaborate with other government departments, nongovernment organisations and voluntary services to deliver a holistic service.

Shift resources into supporting those working with youth in the community.

Use social media to promulgate specific, positive public health messages for young people in the context of their wider needs, rather than in a problem-specific way.

\section{Key workforce recommendations}

Invest in specific training for formal and informal caregivers and develop a career path for formal (and informal) caregivers.

Develop advanced nursing roles (nurse practitioner, clinical nurse specialist) and allied health practitioner roles in multidisciplinary palliative care teams.

Ensure all school nurses are competent and skilled to deliver safe, quality nursing care.

Employ public health nurses in primary care and allocate to schools to deliver school based services and effective health promotion. other resources, capital investment and workforce. Sadly, much extant planning allows the "capital investment tail" (which is usually less that $10 \%$ of total health costs) to wag the "health planning dog". Archaic models of practitionercentred care that are still perpetuated in our hospitals are largely the result of planning that begins with existing IT, capital and workforce - so that ending up where the process started is hardly surprising. The New Zealand clinical vignette model of planning is service-aggregated and not conducted in professional silos (Box; full version online at mja.com.au); it is clinician-led and patientcentred, and results in a forecast of future possible models of care. These possibilities are culled against the following criteria: there can be no loss of quality or access and both ethnic and socioeconomic gaps must be closed; and services that can meet a doubling of demand over the next decade must cost no more than 140\% of today's base (derived from expected growth in GDP). Training purchases and practices are then considered against the requirement that all of the surviving forecasts are adequately addressed. The process is ongoing and iterative, and the consequent planning is consequentially responsive.

Three key principles have been identified with respect to managing the uncertainty inherent in shaping future health workforces. The first is that the health system has a dynamic intelligence. This must apply to the whole of the sector, and in New Zealand it is being created as a virtual agency.

Second, if uncertainty is inevitable, then most of the health workforce needs to be able to be flexibly employed, and quickly retrained and redeployed. An example would be the training of fewer occupational therapists, physiotherapists and speech language therapists and the creation of a large number of new "rehabilitation health workers". The latter would have generic health science education and skills in all three of these areas of therapy. In small centres, their employment would be as a generic rehabilitation worker; in slightly larger centres they may well specialise in cardiac, neurological or mental health rehabilitation; and in a large tertiary centre the specialisation might be as narrow as speech recovery after stroke in a specialised stroke unit. These rehabilitation workers clearly satisfy the criteria for being able to be flexibly employed, and quickly retrained and redeployed. Traditional occupational therapists, physiotherapists and speech language therapists would be consultants in this model of care.

Third, health workers who are slow or expensive to train and expensive to employ, such as doctors, need to be employed in as general a scope of practice as possible and should be limited to roles that can only be satisfactorily performed by someone with their skills and knowledge the aptly-cited "work at the top end of their licence" situation. In addition to future-proofing through generalism, the quality and cost of health care appear to be favourably influenced by an increased concentration of general medical practitioners, and unfavourably influenced by an increased concentration of specialist medical practitioners. ${ }^{19}$ Advocacy of general medical practice requires a recovery of relative status for doctors so employed and this in turn will require a portfolio of attractive role models and enjoyable student exposures, well supported training schemes - the new general 
medical practice training program in New Zealand is to be introduced in December 2012 - and of relatively generous productivity-related reward schema. ${ }^{19-22}$

\section{Towards a sustainable and fit-for-purpose New Zealand health workforce}

An affordable, sustainable and fit-for-purpose New Zealand health workforce can only be achieved by way of a clinician-led and intelligence-informed innovative reform of funding and reward systems, and of service configurations and models of care across the health and disability sector. Given the intrinsic uncertainty, this intelligence must be both inclusive and dynamic, and any consequent planning needs to create and maintain a core workforce that can be employed flexibly and redeployed quickly, and to ensure that those necessary elements of the health workforce that are slow and expensive to train have a scope of practice that is as general as possible, while such practitioners work at the top end of their licence.

Competing interests: No relevant disclosures.

Provenance: Commissioned; externally peer reviewed.

1 Bramley D, Hebert P, Tuzzio L, Chassin M. Disparities in indigenous health: a cross-country comparison between New Zealand and the United States. Am J Public Health 2005; 95: 844-850.

2 Gorman DF. Closing the gap. Intern Med J 2008; 38: 153-155.

3 Fogel RW. The escape from hunger and premature death, 1700-2100: Europe, America and the Third World Cambridge: Cambridge University Press, 2004

4 World Health Organization. The world health report 2006 - working together for health. Geneva: WHO, 2006. http://www.who.int/whr/ 2006/en/ (accessed Nov 2008)

5 Zurn P. Dumont JC. Health workforce and international migration: can New Zealand compete? OECD Health Working Paper 33 (WHO DELSA/ HEA/WD/HWP [2008] 3). Paris: Organisation for Economic Cooperation and Development, Directorate for Employment, Labour and
Social Affairs, 2008. http://www.oecd.org/dataoecd/46/4l/ 40673065.pdf (accessed Jul 2012).

6 Gorman DF. Citizenship, health and the challenge of clinical leadership. Intern Med J 2010; 40: 739-741.

7 New Zealand Institute of Economic Research. Ageing New Zealand and health and disability services: demand projections and workforce implications, 2001-2021. Wellington: Ministry of Health, 2004. http:// www.waikatodhb.govt.nz/file/fileid/10429 (accessed Jul 2012).

8 Maniparathy M. Productivity performance of New Zealand hospitals 1998/99 to 2005/06. Wellington: New Zealand Business Roundtable, 2008. http://www.nzbr.org.nz/site/nzbr/files/publications/ productivity\%20performance\%20of\%20nz\%20public\%20hospitals. pdf (accessed Jul 2012)

9 Levinson W, Lurie N. When most doctors are women: what lies ahead? Ann Intern Med 2004; 14l: 471-474.

10 Schofield DJ, Beard JR. Baby boomer doctors and nurses: demographic change and transitions to retirement. Med J Aust 2005; 183: 80-83.

11 Gorman DF, Scott PJ. The social distortion of medical practice. Medicine Today 2003; 4: 75-77.

12 Gorman DF. The utility of idealised patient journeys as a centre-piece of health workforce planning. Asia Pacific J Health Manage 2010; 5: $8-13$

13 Christensen CM, Bohmer R, Kenagy J. Will disruptive innovations cure health care? Harv Bus Rev 2000; 78: 102-112.

14 Forbes T, Hallier J, Kelly L. Doctors as managers: investors and reluctants in a dual role. Health Serv Manage Res 2004; 17: 167-176.

15 Gorman DF, Brooks PM. On solutions to the shortage of doctors in Australia and New Zealand. Med J Aust 2009; 190: 152-156.

16 Gorman D, Thompson M. Encouraging and rewarding the good behaviour of healthcare providers. Intern Med J 2011; 41: 585-587.

17 Jiang HJ, Stryer D. Friedman B. Andrews R. Multiple hospitalizations for patients with diabetes. Diabetes Care 2003; 26: 1421-1426.

18 Chey WD, Wong BC; Practice Parameters Committee of the American College of Gastroenterology. American College of Gastroenterology guideline on the management of Helicobacter pylori infection. Am J Gastroenterol 2007; 102: 1808-1825.

19 Baicker K, Chandra A. Medicare spending, the physician workforce, and beneficiaries' quality of care. Health Aff (Millwood) 2004; Suppl Web Exclusives: W4-184-W197. http://content.healthaffairs.org/cgi/ content/full/hlthaff.w4.184vl/DCl (accessed Nov 2008)

20 Bodenheimer T. Primary care - will it survive? N Engl J Med 2006; 355: 861-864.

21 Smith SR. A recipe for medical schools to produce primary care physicians.N Engl J Med 2011; 364: 496-497.

22 Woo B. Primary care - the best job in medicine? N Engl J Med 2006; 355: $864-866$ 